\title{
In-Situ Oxygen Measurement by a YSZ Oxygen Sensor During Sewage Sludge Combustion
}

\author{
Guangwei Wang ${ }^{1,2, *}$, Hongzhen Chen ${ }^{2}$ \\ ${ }^{1}$ Department of Chemistry and Chemical Engineering, Zunyi Normal University, Zunyi, Guizhou, P. \\ R. China, 563006 \\ ${ }^{2}$ Chongqing Institute of Green and Intelligent Technology (CIGIT), Chinese Academy of Sciences, \\ Chongqing, P. R. China, 400714 \\ "E-mail: wangguangwei@ vip.gyig.ac.cn
}

doi: $10.20964 / 2020.08 .45$

Received: 2 April 2020 / Accepted: 24 May 2020 / Published: 10 July 2020

Combustion experiments with in-situ oxygen measurement were performed to evaluate the impacts of oxygen alteration on the incineration of dried sewage sludge. Consequently, temperature was linked to the sludge combustion process, and the effects were mainly shown in the reaction rate of sludge combustion, EMF and $\theta$ curves, where the combustion temperature of $800{ }^{\circ} \mathrm{C}$ decreased much more rapidly than that of $600{ }^{\circ} \mathrm{C}$, and the combustion process reached a final stable state much faster when a high temperature was adopted than when a low temperature was adopted. The oxygen concentration was an important factor for the combustion of sewage sludge since it significantly influenced the oxidation rates of the organic compounds in the sludge samples. However, the amount of oxygen consumption was not affected by the oxygen concentration if the sludge was well combusted; it directly proportionally changed with the change in sludge amount. This relationship can be potentially used to evaluate the pollution levels in solid wastes, such as sewage sludge, which will be very interesting and worthy of further investigation. Organic carbon in organic compounds was converted into inorganic carbon during the sludge combustion process and resulted in almost $100 \%$ of TOC removal. Probably due to the coalescence of the produced phosphorus oxide with non-flammable inorganic substances, the TP levels were much higher than the TOC, TN, TS and TCl levels in the ashes. For the extensive thermal disposal of sewage sludge, measures must be taken to mitigate the potential risk of gaseous toxic emissions produced by these treatments.

Keywords: combustion; sewage sludge; oxygen concentration; sensor; in-situ measurement

\section{$\underline{\text { FULL TEXT }}$}


(C) 2020 The Authors. Published by ESG (www.electrochemsci.org). This article is an open access article distributed under the terms and conditions of the Creative Commons Attribution license (http://creativecommons.org/licenses/by/4.0/). 